\title{
A randomised controlled study of preoperative oral carbohydrate loading versus fasting in patients undergoing colorectal surgery
}

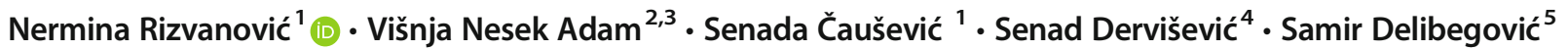

Accepted: 5 July 2019 / Published online: 15 July 2019

(C) The Author(s) 2019

\begin{abstract}
Purpose This study aimed to evaluate the effect of preoperative carbohydrate oral (CHO) loading on the postoperative metabolic and inflammatory response, perioperative discomfort and surgical clinical outcomes in open colorectal surgery compared with a conventional fasting protocol.

Methods Fifty patients were randomly allocated to either the intervention group (CHO), to receive preoperative oral carbohydrate supplementation, or the control group (FAST), to undergo preoperative fasting. Insulin resistance, insulin sensitivity, the Glasgow Prognostic Score (GPS) and IL-6 levels were analysed at $06 \mathrm{~h}$ on the day of surgery $\left(\mathrm{T}_{1}\right), 6 \mathrm{~h}$ after surgery $\left(\mathrm{T}_{2}\right)$ and at $06 \mathrm{~h}$ on postoperative day $1\left(\mathrm{~T}_{3}\right)$ and postoperative day $2\left(\mathrm{~T}_{4}\right)$. Thirst, hunger, dry mouth, weakness, anxiety and pain were assessed using the visual analogue scale (VAS) prior to anaesthesia induction and at $0-4,4-8,8-12$ and $12-24 \mathrm{~h}$ after surgery. Surgical clinical outcomes included the return of gastrointestinal function, time to independent ambulation and postoperative discharge day.

Results Postoperative insulin resistance was $30 \%$ lower $(p<0.03)$ and insulin sensitivity was $15 \%$ higher $(p<0.05)$ in the CHO group than in the FAST group. The GPS was lower in the CHO group at $\mathrm{T}_{1}(p<0.001), \mathrm{T}_{3}(p<0.01)$ and $\mathrm{T}_{4}(p<0.004)$. IL-6 serum levels were lower at the analysed postoperative time points in the CHO group $(p<0.001)$. The VAS well-being score was lower in the intervention group $(p<0.001)$; however, the VAS pain score was not significantly different between the groups. The evaluated surgical outcomes appeared earlier in the CHO group $(p<0.001)$.

Conclusion A preoperative $\mathrm{CHO}$ drink reduced the postoperative metabolic and inflammatory response and improved subjective well-being and surgical clinical outcomes but did not diminish the VAS pain score.
\end{abstract}

Keywords Insulin resistance $\cdot$ Preoperative fasting $\cdot$ Preoperative carbohydrate $\cdot$ Visual analogue scale $\cdot$ Colorectal surgery

Nermina Rizvanović

rizvanovic.nermina@gmail.com

1 Department of Anesthesiology and Intensive Care Unit, Cantonal Hospital Zenica, 67 Crkvice St, 72000 Zenica, Bosnia and Herzegovina

2 University Department of Anesthesiology, Resuscitation and Intensive Care, Clinical Hospital Sveti Duh, 64 Sveti Duh St, 10 000 Zagreb, Croatia

3 Faculty of Medicine, J.J. Strossmayer Osijek, Osijek, Croatia

4 Department of Surgery, Cantonal Hospital Zenica, 67 Crkvice St, 72 000 Zenica, Bosnia and Herzegovina

5 Department of Surgery, University Clinical Center Tuzla, Trnovac St, 75000 Tuzla, Bosnia and Herzegovina

\section{Introduction}

Preoperative fasting increases perioperative insulin resistance (PIR) and patient discomfort. Surgery itself, especially a major procedure such as colorectal surgery, induces an endocrine and inflammatory stress response and contributes to PIR [1].

PIR has a central role in the metabolic response to surgical injury. Contra-regulating hormones diminish peripheral insulin activity. PIR is a state of reduced insulin-mediated glucose uptake in skeletal muscles and adipose tissue, with an increased glucose release due to hepatic gluconeogenesis and hyperglycaemia. A catabolic state occurs with the depleted storage of glycogen via glycogenolysis, muscle protein loss and lipolysis [2]. The purpose of PIR is to provide energy and glycaemic substrates to glucose-dependent tissues. PIR is an adaptive mechanism, but it can be harmful if left untreated, 
increasing postoperative morbidity and mortality and prolonging the hospital stay [3].

Strategies to reduce the postoperative stress response and PIR include shortening the preoperative fasting time via preoperative carbohydrate oral (CHO) drink administration. Preoperative fasting is the first step in PIR development [4]. The traditional fasting time of 6-8 $\mathrm{h}$ before elective surgery to prevent pulmonary aspiration usually extends up to $12 \mathrm{~h}$ in anaesthetic practise. Overnight fasting is a physiological state of reduced insulin sensitivity due to the normal hormonal diurnal rhythm. If patients undergo surgery in the prolonged fasted state, insulin resistance may begin even before surgery. A preoperative $\mathrm{CHO}$ drink acts as a morning meal, improves insulin sensitivity and propels the patient's metabolic state towards anabolism [5]. The effectiveness of CHO loading for the occurrence of PIR has been assessed by many investigators, but various methodological approaches and study protocols have resulted in contradictory findings between studies [6-8].

Preoperative fasting and surgical tissue damage activate inflammatory pathways mediated by various cytokines [9] Increasing the level of interleukin 6 (IL-6), reduces insulin action and contributes to PIR. IL-6 stimulates the acute phase of protein synthesis, such as C-reactive protein (CRP), and inhibits the synthesis of albumin [10]. An increased CRP level after colorectal surgery is a reliable marker of the systemic inflammatory response (SIRS) [11]. A decreasing level of postoperative albumin is correlated with previous malnutrition and the severity of illness [12]. The ratio of inflammatory to nutritional factors, CRP/albumin, is known as the Glasgow Prognostic Score (GPS), which is a useful tool for predicting infectious complications, morbidity and mortality after colorectal surgery [13].

The present study evaluated the overall effectiveness of a preoperative $\mathrm{CHO}$ drink in terms of the postoperative metabolic and inflammatory response, perioperative discomfort and surgical clinical outcomes in open colorectal surgery as a model of major surgery.

The aim of this study was to compare the differences between preoperative $\mathrm{CHO}$ loading and a conventional fasting protocol on the PIR, GPS score, IL-6 level, subjective patient well-being, visual analogue scale (VAS) pain score and surgical clinical outcomes.

\section{Methods}

\section{Patients and study design}

This prospective, randomised controlled clinical study was carried out in the Department of Anesthesiology, Intensive Care Unit and Department of Surgery at Cantonal Hospital in Zenica, Bosnia and Herzegovina. After obtaining ethical committee approval and written patient consent, 50 patients with an American Society of Anesthesiologist (ASA) physical status of I-II, between 18 and 70 years of age and scheduled for elective open colorectal surgery were included in this study. The study was registered in ClinicalTrials.gov (number NCT03793036).

Patients with previous treatment for colorectal cancer, disseminated malignant disease, an increased risk of gastric content aspiration, body mass index below 20 or above $30 \mathrm{~kg} / \mathrm{m}^{2}$ or an overall score $\geq 3$ according to the Nutritional Risk Screening 2002 (NRS-2002) were excluded from the study [14]. Additional exclusion criteria were emergency colorectal surgery, diabetes mellitus, inflammatory bowel disease, immunomodulatory therapy, a history of allergy to any study drug and the patient's refusal to participate in the study. The day before surgery, patients who fulfilled the study criteria were randomly allocated into two groups of 25 patients. Randomisation was performed using computer-generated random numbers indicating the treatment, which were held in sealed opaque envelopes. The researcher who conducted the randomisation and opened the envelopes the night before surgery was blinded by the study protocol, as were the staff involved in the medical procedures and data collection process. The progress of the patients throughout the randomised trial is shown in Fig. 1.

Patients in the FAST group (control group) fasted for $8 \mathrm{~h}$ before surgery. Patients in the $\mathrm{CHO}$ group (intervention group) received $400 \mathrm{~mL}$ of a clear carbohydrate drink $(12.5 \mathrm{~g} / 100 \mathrm{~mL}$ maltodextrin, $50 \mathrm{kcal} / 100 \mathrm{~mL}, \mathrm{pH} 5.0)$ at $22 \mathrm{~h}$ on the evening before surgery and another $200 \mathrm{~mL}$ of the carbohydrate drink on the day of surgery, $2 \mathrm{~h}$ before anaesthesia induction. The night before surgery, diazepam $5 \mathrm{mg}$ (intramuscular) and low-molecular-weight heparin (subcutaneous) were administered to all patients. Preoperatively, there was no intravenous administration of the fluids. Open radical resection of colorectal cancer was performed in all patients under general endotracheal anaesthesia. Sixty minutes before surgery, a prophylactic dose of the first generation of cephalosporin was administered intravenously. Three minutes before anaesthesia induction, all patients received midazolam $0.05 \mathrm{mg} / \mathrm{kg}$ intravenously and were preoxygenated with $100 \%$ oxygen by facial mask. Anaesthesia was induced with propofol $3 \mathrm{mg} / \mathrm{kg}$, fentanyl $3 \mu \mathrm{g} / \mathrm{kg}$ and pancuronium-bromide $0.1 \mathrm{mg} / \mathrm{kg}$. Balanced anaesthesia was maintained using sevoflurane minimum alveolar concentration $0.5-1 \%$ and $\mathrm{N}_{2} \mathrm{O} 50 \%$ in oxygen, at a total flow of $2 \mathrm{~L} / \mathrm{min}$ and with intermittent bolus doses of fentanyl and pancuronium. Intraoperative fluid management was limited to a glucose-free solution and no exogenous insulin administration. At the end of surgery, the neuromuscular block was reversed with neostigmine $0.05 \mathrm{mg} / \mathrm{kg}$ and atropine $0.02 \mathrm{mg} / \mathrm{kg}$. The patients were extubated when fully awake. Postoperative care was standardised as clinically indicated and 
Fig. 1 CONSORT flow diagram of the study design

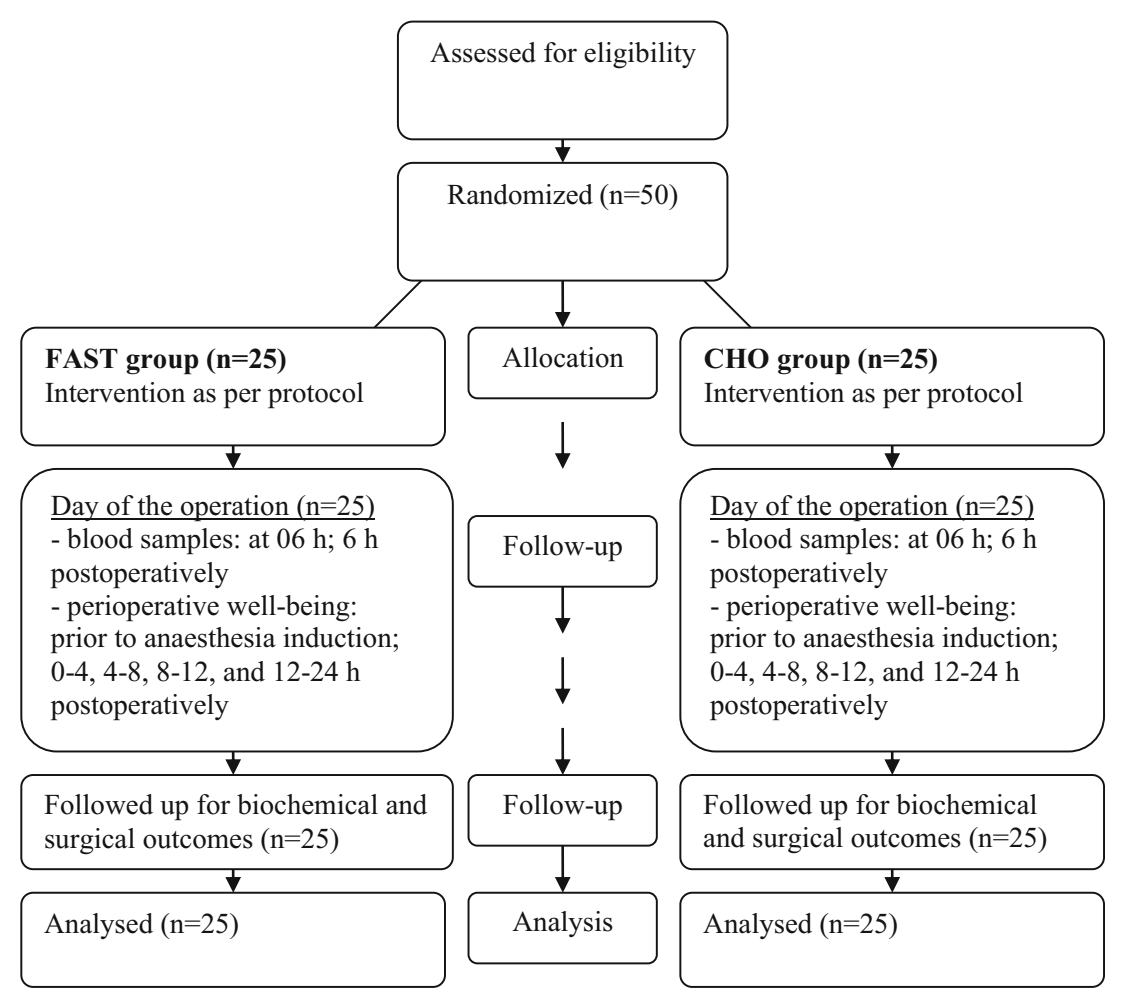

a free fluid regimen was permitted. Early postoperative mobilisation was recommended.

\section{Data collection and definitions}

Clinical biochemical parameters were assessed from peripheral venous blood samples, taken at $06 \mathrm{~h}$ on the day of surgery ( $T_{1}$, basal value), $6 \mathrm{~h}$ after surgery $\left(\mathrm{T}_{2}\right)$, at $06 \mathrm{~h}$ on postoperative day $1\left(\mathrm{~T}_{3}\right)$ and at $06 \mathrm{~h}$ on postoperative day $2\left(\mathrm{~T}_{4}\right)$. Serum levels of glucose, insulin, CRP, albumin and IL-6 were evaluated. Postoperatively, patients did not receive intravenous glucose or oral nutrition $6 \mathrm{~h}$ prior to the morning testing, from midnight to $06 \mathrm{~h}$. Serum glucose was measured using the hexokinase/glucose-6-phosphate dehydrogenase enzymatic method, for which the range of normality (r.n.) is 3.3$6.1 \mathrm{mmol} / \mathrm{L}$. Serum insulin (r.n. $3-17 \mu \mathrm{U} / \mathrm{mL}$ ) was determined by a solid-phase, two-site chemiluminescent immunometric assay. Insulin resistance was calculated using the homeostasis model assessment of insulin resistance (HOMA-IR), according to the following equation: HOMA$\mathrm{IR}=$ [fasting insulin $(\mu \mathrm{U} / \mathrm{mL}) \times$ fasting glucose $(\mathrm{mmol} / \mathrm{L})] /$ 22.5. HOMA-IR $>1$ indicated the presence of insulin resistance. Insulin sensitivity (r.n. 100\%) was calculated using the following equation: HOMA-ISI (insulin sensitivity index) = $1 / \log /[$ fasting glucose $(\mathrm{mmol} / \mathrm{L})+$ fasting insulin $(\mu \mathrm{U} / \mathrm{mL})]$. HOMA-IR and ISI were processed with a computer model HOMA 2 Calculator version 2.2. Serum CRP (r.n. 0-5 mg/ L) was monitored using an automatic immunonephelometry technique. Serum albumin (r.n. 35-48 g/L) was analysed using the bromocresol green colorimetric method. The GPS was calculated as follows: an elevated level of CRP $>10 \mathrm{mg} / \mathrm{L}$ and hypoalbuminemia $<35 \mathrm{~g} / \mathrm{L}$ were allocated a score of 2 , and one or neither of these biochemical abnormalities was assigned a score of 1 or 0 , respectively. The serum IL- 6 concentration (r.n. $0-5.9 \mathrm{pg} / \mathrm{mL}$ ) was measured using enzymelinked immunosorbent assay test kits.

Subjective patient well-being and pain scores were assessed prior to anaesthesia induction and were repeated at $0-4,4-8,8-12$ and $12-24 \mathrm{~h}$ after surgery. Thirst, hunger, mouth dryness, anxiety, weakness, pain at rest and pain with mobilisation scores were measured using a $10-\mathrm{cm}$ horizontal VAS scale. The patients were instructed on how to use the VAS scale. The scales were limited by a vertical line at the left end that represented 'no symptom' (score of 0 ) and a vertical line at the right end that represented 'the worst imaginable symptom' (score of 10). The patients marked somewhere on the VAS line. The distance from 0 to the patient's mark on the VAS line determined the score of the perceived symptom. The combination of metamizole sodium $1.25 \mathrm{~g}$ and tramadol hydrochloride $100 \mathrm{mg}$ was administered intravenously for a VAS score $>3$ or if the patient reported pain. If analgesia was not achieved or the VAS score was $>5$, an additional dose of tramadol hydrochloride $25 \mathrm{mg}$ was provided. The time to the first postoperative analgesic dose and the number of additional analgesic doses were noted.

Nausea was defined as an unpleasant sensation referring to a desire to vomit without expulsive muscular movement. Vomiting was defined as the forceful expulsion of even a 
small amount of gastrointestinal contents through the mouth. The patients were questioned about the presence of nausea and vomiting at five study time points. The answer 'no' was graded as 1 , and the answer 'yes' was graded as 2 . The presence of nausea during $30 \mathrm{~min}$, more than one episode of vomiting during $15 \mathrm{~min}$ or the patient's request for antiemetic drugs was treated with thiethylperazine $10 \mathrm{mg}$ intravenously. The number of antiemetic drug doses was recorded.

Surgical outcomes were evaluated by the postoperative return of gastrointestinal function, time to independent ambulation and postoperative discharge day. The sounds of the bowel were analysed by an abdominal auscultation at $24,36,48,60$, 72 and $80 \mathrm{~h}$, postoperatively. The time of the first postoperative flatus and the time of the first postoperative defecation were recorded. In addition, gender, age, body weight, body mass index, NRS-2002 score, ASA physical status class, type of surgery, operation time and intraoperative blood loss were collected.

\section{Statistical analysis}

The data analysis was performed using the Statistical Package for the Social Sciences (SPSS v23.0; IBM Corp., Armonk, NY, USA). The sample size was estimated using sample size calculator software and a power analysis with a $95 \%$ confidence interval and power of $80 \%$. Statistical significance was considered $p<0.05$. The calculation indicated that 19 patients per group would be sufficient to detect a $50 \%$ difference for insulin resistance between the groups. Assuming dropout led to a total sample size of 50 patients. Categorical variables were analysed using Pearson's chi-squared test and presented as the frequency and relative number of cases (percentage). Parametric variables were expressed as the mean and standard deviation or median and range as appropriate. For comparisons, Student's $t$ test, a one-way analysis of variance (ANOVA) or the Mann-Whitney $U$ test was used, depending on the type and distribution of the data.

\section{Results}

All 50 of the recruited participants completed the study and were included in the analysis. There were no statistically significant differences in the demographic or surgical data between the groups, which is summarised in Table 1.

\section{Clinical biochemical parameters}

Insulin resistance parameters, i.e., serum glucose, insulin and HOMA-IR levels, were higher in the FAST group than in the $\mathrm{CHO}$ group during all study periods. HOMA-ISI levels were lower in the FAST group than in the $\mathrm{CHO}$ group. Statistical significance of the differences between groups is presented in Table 2.

Table 1 Demographic characteristics of the groups

\begin{tabular}{llll}
\hline Group parameters & FAST group $(n=25)$ & CHO group $(n=25)$ & $p$ \\
\hline Gender, male/female, $n(\%)$ & $13 / 12(52 / 48)$ & $14 / 11(56 / 44)$ & 0.777 \\
Age (years) mean $\pm \mathrm{SD}$ & $60.2 \pm 9.7$ & $81.0 \pm 7.3$ & 0.758 \\
Body weight $(\mathrm{kg})$ mean $\pm \mathrm{SD}$ & $79.3 \pm 12$ & $26.4 \pm 4.5$ & 0.313 \\
Body mass index $\left(\mathrm{kg} / \mathrm{m}^{2}\right)$ mean $\pm \mathrm{SD}$ & $24.7 \pm 1.6$ & $13 / 12(52 / 48)$ & 0.116 \\
NRS-2002 score I/II, $n(\%)$ & $15 / 10(60 / 40)$ & $8 / 17(32 / 68)$ & \\
ASA I/II, $n(\%)$ & $7 / 18(28 / 72)$ & $9(36)$ & $7(28)$ \\
Type of surgery, $n(\%)$ & & $4(16)$ & $4(16)$ \\
Hemicolectomia right & $8(32)$ & $1(4)$ \\
Operation Dixon & $9(36)$ & $143.2 \pm 39.4$ \\
Operation Hartman & $3(12)$ & & 0.785 \\
Operation Miles & $5(20)$ & $20(80)$ \\
Proctocolectomia & $0(0)$ & $5(20)$ \\
Operation time (min) mean $\pm \mathrm{SD}$ & $137.6 \pm 28.9$ & & 0.860 \\
Blood loss, $n(\%)$ & $21(84)$ & $4(16)$ & 0.570 \\
$<300$ ml & & 0.713 \\
$>300$ ml & & &
\end{tabular}

Student's $t$ test and $x^{2}$ test were used for the analysis, and $p<0.05$ was considered statistically significant. SD, standard deviation; FAST group, preoperative fasting group; $C H O$ group, preoperative carbohydrate loading group; NRS-2002, Nutrition Risk Score-2002; ASA, American Society of Anesthesiologists 
Table 2 Mean values of insulin resistance parameters according to the groups and study time points

\begin{tabular}{|c|c|c|c|c|c|c|}
\hline \multirow[t]{2}{*}{ Parameter } & \multirow[t]{2}{*}{ Time } & \multicolumn{2}{|c|}{ FAST group $(n=25)$} & \multicolumn{2}{|c|}{$\mathrm{CHO}$ group $(n=25)$} & \multirow[t]{2}{*}{$p$} \\
\hline & & Mean \pm SD & $95 \% \mathrm{CI}$ & Mean \pm SD & $95 \% \mathrm{CI}$ & \\
\hline \multirow[t]{4}{*}{ Glucose (mmol/L) } & $\mathrm{T}_{1}$ & $6.5 \pm 1.1$ & $1.0-2.0$ & $5.0 \pm 0.6$ & $1.0-2.0$ & 0.001 \\
\hline & $\mathrm{T}_{2}$ & $7.5 \pm 1.5$ & $0.9-2.4$ & $5.8 \pm 1.1$ & $0.9-2.4$ & 0.001 \\
\hline & $\mathrm{T}_{3}$ & $7.3 \pm 1.6$ & $-0.1-1.6$ & $6.6 \pm 1.4$ & $0.1-1.6$ & 0.102 \\
\hline & $\mathrm{T}_{4}$ & $6.7 \pm 1.1$ & $0.2-1.5$ & $5.8 \pm 0.9$ & $0.2-1.5$ & 0.005 \\
\hline \multirow[t]{4}{*}{ Insulin $(\mu \mathrm{U} / \mathrm{mL})$} & $\mathrm{T}_{1}$ & $5.4 \pm 0.7$ & $1.0-1.9$ & $3.8 \pm 0.8$ & $1.0-1.9$ & 0.001 \\
\hline & $\mathrm{T}_{2}$ & $9.8 \pm 1.6$ & $3.0-4.4$ & $6.0 \pm 0.5$ & $3.0-4.4$ & 0.001 \\
\hline & $\mathrm{T}_{3}$ & $17.6 \pm 4.1$ & $6.6-10.0$ & $9.3 \pm 1.1$ & $6.6-10.1$ & 0.001 \\
\hline & $\mathrm{T}_{4}$ & $13.1 \pm 1.6$ & $5.3-6.8$ & $7.0 \pm 0.9$ & $5.3-6.8$ & 0.001 \\
\hline \multirow[t]{4}{*}{ HOMA-IR } & $\mathrm{T}_{1}$ & $0.7 \pm 0.1$ & $0.2-0.3$ & $0.4 \pm 0.0$ & $0.2-0.3$ & 0.001 \\
\hline & $\mathrm{T}_{2}$ & $1.4 \pm 0.2$ & $0.4-0.6$ & $0.8 \pm 0.0$ & $0.4-0.6$ & 0.001 \\
\hline & $\mathrm{T}_{3}$ & $2.4 \pm 0.5$ & $0.9-1.4$ & $1.2 \pm 0.1$ & $0.9-1.4$ & 0.001 \\
\hline & $\mathrm{T}_{4}$ & $1.7 \pm 0.1$ & $0.7-0.8$ & $0.9 \pm 0.1$ & $0.7-0.8$ & 0.001 \\
\hline \multirow[t]{4}{*}{ HOMA-ISI } & $\mathrm{T}_{1}$ & $136.8 \pm 21.3$ & $83.4-54.5$ & $205.8 \pm 28.8$ & $83.4-54.5$ & 0.001 \\
\hline & $\mathrm{T}_{2}$ & $74.8 \pm 12.9$ & $54.6-41.0$ & $122.7 \pm 10.8$ & $54.6-41.0$ & 0.001 \\
\hline & $\mathrm{T}_{3}$ & $43.1 \pm 10.8$ & $43.5-31.3$ & $80.6 \pm 10.6$ & $43.5-31.3$ & 0.001 \\
\hline & $\mathrm{T}_{4}$ & $56.8 \pm 5.8$ & $56.1-43.8$ & $106.8 \pm 14.1$ & $56.2-43.7$ & 0.001 \\
\hline
\end{tabular}

Student's $t$ test was used for the analysis, and $p<0.05$ was considered statistically significant

$S D$, standard deviation; $C I$, confidence interval; FAST group, preoperative fasting group; CHO group, preoperative carbohydrate loading group; HOMA$I R$, homeostasis model assessment of insulin resistance; HOMA-ISI, homeostasis model assessment of insulin sensitivity index; $T_{l}, 06 \mathrm{~h}$ on the day of surgery; $T_{2}, 6 \mathrm{~h}$ after surgery; $T_{3}, 06 \mathrm{~h}$ on postoperative day $1 ; T_{4}, 06 \mathrm{~h}$ on postoperative day 2

The mean value of HOMA-IR in the FAST group increased by $85 \% 6 \mathrm{~h}$ after surgery and $76 \%$ on postoperative day 1 , while there was a $27 \%$ decrease on postoperative day 2 . In the CHO group, the mean value of HOMA-IR increased by $74 \%$ $6 \mathrm{~h}$ after surgery and $55 \%$ on postoperative day 1 , while there was a $25 \%$ decrease on postoperative day 2 . The total increase in HOMA-IR was 30\% lower in the CHO group than in the FAST group $(p<0.03)$.

HOMA-ISI had a $44 \%$ decline at $6 \mathrm{~h}$ after surgery and a $41 \%$ decline on postoperative day 1 in the FAST group, followed by a $31 \%$ increase on postoperative day 2 . In the CHO group, HOMA-ISI decreased by $39 \% 6 \mathrm{~h}$ after surgery and $32 \%$ on postoperative day 1 , while it increased by $32 \%$ on postoperative day 2. The total reduction in HOMA-ISI was $54 \%$ in the FAST group versus $39 \%$ in the $\mathrm{CHO}$ group $(p<0.05)$.

Inflammatory response parameters were elevated after surgery in both groups, except for serum albumin, which decreased. Significantly greater CRP levels were seen in the FAST group, with the peak on postoperative day 2 in both groups. Serum albumin decreased significantly between each studied time point in the FAST group $(p<0.05)$ but did not decrease significantly in the $\mathrm{CHO}$ group. Higher GPS scores were found in the FAST group, with a maximum grade of 2 in $25(100 \%)$ patients versus $17(68 \%)$ patients in the $\mathrm{CHO}$ group on postoperative day $2(p<0.004)$. Significantly higher levels of IL-6 were displayed in the FAST group. The peak was recorded $6 \mathrm{~h}$ postoperatively and further declined, but there was no return to the baseline in any group (Table 3).

\section{Subjective patient well-being parameters and VAS pain score}

The VAS scores of the subjective well-being parameters were significantly higher in patients who fasted than in those who $\mathrm{CHO}$ loaded preoperatively. The incidence of nausea and the number of antiemetic requests was significantly higher in the FAST group ( $p<0.02$ and $p<0.04$, respectively). The incidence of vomiting was not significantly different between the groups (Table 4).

There were no statistically significant differences in the VAS pain score or the number of additional analgesic doses between the study groups. The time to first postoperative analgesic dose was shorter in the FAST group (Table 5).

\section{Surgical clinical outcomes}

Participants in the $\mathrm{CHO}$ group had a significantly faster return of gastrointestinal function; intestinal sounds were heard earlier, and the times to first flatus, first defecation and oral intake were shorter. Independent ambulation and postoperative discharge day occurred earlier in the $\mathrm{CHO}$ group (Table 6). 
Table 3 Mean values of inflammatory response parameters according to the groups and study time points

\begin{tabular}{|c|c|c|c|c|c|c|}
\hline \multirow[t]{2}{*}{ Parameter } & \multirow[t]{2}{*}{ Time } & \multicolumn{2}{|c|}{ FAST group $(n=25)$} & \multicolumn{2}{|c|}{$\mathrm{CHO}$ group $(n=25)$} & \multirow[t]{2}{*}{$p$} \\
\hline & & Mean \pm SD & $95 \% \mathrm{CI}$ & Mean \pm SD & $95 \% \mathrm{CI}$ & \\
\hline \multirow[t]{4}{*}{ CRP (mg/L) } & $\mathrm{T}_{1}$ & $14.9 \pm 3.7$ & $7.6-11.1$ & $5.5 \pm 2.2$ & $7.6-11.1$ & 0.001 \\
\hline & $\mathrm{T}_{2}$ & $52.7 \pm 17.2$ & $27.0-41.8$ & $18.3 \pm 5.4$ & $27.0-41.8$ & 0.001 \\
\hline & $\mathrm{T}_{3}$ & $93.8 \pm 16.9$ & $22.3-41.8$ & $62.9 \pm 12.7$ & $22.3-39.4$ & 0.001 \\
\hline & $\mathrm{T}_{4}$ & $125.3 \pm 21.9$ & $31.9-51.0$ & $83.8 \pm 9.1$ & $31.8-51.1$ & 0.001 \\
\hline \multirow[t]{4}{*}{ Albumin $(\mathrm{g} / \mathrm{L})$} & $\mathrm{T}_{1}$ & $40.4 \pm 3.2$ & $-0.8-2.7$ & $39.4 \pm 3.0$ & $-0.8-2.7$ & 0.294 \\
\hline & $\mathrm{T}_{2}$ & $34.8 \pm 3.1$ & $-3.0-0.4$ & $36.1 \pm 2.9$ & $-3.0-0.4$ & 0.133 \\
\hline & $\mathrm{T}_{3}$ & $31.7 \pm 2.2$ & $-3.4-0.7$ & $33.8 \pm 2.6$ & $3.4-0.7$ & 0.030 \\
\hline & $\mathrm{T}_{4}$ & $28.6 \pm 2.1$ & $4.9-2.3$ & $32.2 \pm 2.4$ & $-4.9-2.3$ & 0.001 \\
\hline \multirow[t]{4}{*}{ GPS } & $\mathrm{T}_{1}$ & $0.9 \pm 0.4$ & $0.4-0.9$ & $0.2 \pm 0.5$ & $0.4-0.9$ & 0.001 \\
\hline & $\mathrm{T}_{2}$ & $1.4 \pm 0.5$ & $-1.8-0.4$ & $1.3 \pm 0.4$ & $-1.8-0.4$ & 0.421 \\
\hline & $\mathrm{T}_{3}$ & $1.8 \pm 0.3$ & $0.0-05$ & $1.5 \pm 0.5$ & $0.0-0.5$ & 0.011 \\
\hline & $\mathrm{T}_{4}$ & $2.0 \pm 0.0$ & $0.0-0.4$ & $1.7 \pm 0.4$ & $0.0-0.4$ & 0.004 \\
\hline \multirow[t]{4}{*}{ IL-6 (pg/mL) } & $\mathrm{T}_{1}$ & $5.3 \pm 3.0$ & $-0.3-2.5$ & $4.2 \pm 1.8$ & $-0.3-36.3$ & 0.123 \\
\hline & $\mathrm{T}_{2}$ & $347.4 \pm 155.1$ & $159.6-287.8$ & $123.7 \pm 36.3$ & $158.2-289.1$ & 0.001 \\
\hline & $\mathrm{T}_{3}$ & $143.2 \pm 41.5$ & $77.2-112.4$ & $48.4 \pm 14.0$ & $76.9-112.7$ & 0.001 \\
\hline & $\mathrm{T}_{4}$ & $48.5 \pm 17.2$ & $20.8-36.3$ & $19.9 \pm 8.6$ & $20.7-36.3$ & 0.001 \\
\hline
\end{tabular}

Student's $t$ test was used for the analysis, and $p<0.05$ was considered statistically significant

$S D$, standard deviation; $C I$, confidence interval; FAST group, preoperative fasting group; CHO group, preoperative carbohydrate loading group; CRP, Creactive protein; GPS, Glasgow Prognostic Score; $I L-6$, interleukin $6 ; T_{1}, 06 \mathrm{~h}$ on the day of surgery; $T_{2}, 6 \mathrm{~h}$ after surgery; $T_{3}, 06 \mathrm{~h}$ on postoperative day 1 ; $T_{4}, 06 \mathrm{~h}$ on postoperative day 2

\section{Discussion}

While previous studies have focused on certain aspects of preoperative $\mathrm{CHO}$ loading in patients undergoing colorectal surgery, our study provides a comprehensive assessment of all the aspects considered to be the effects of a CHO drink. This study encompassed biochemical outcomes (metabolic and inflammatory responses), psychological outcomes (patient wellbeing and pain scores) and functional surgical outcomes (return of gastrointestinal function, time to independent ambulation and postoperative discharge day).

The present study suggested that a $\mathrm{CHO}$ drink taken the evening before open colorectal surgery and $2 \mathrm{~h}$ before the induction of anaesthesia provided better postoperative glycaemic control, reduced PIR by $30 \%$, enhanced insulin sensitivity by $15 \%$ and attenuated the inflammatory response in terms of lower GPS scores and IL-6 levels compared with the traditional concept of preoperative fasting.

Although all participants were normoglycaemic upon admission to the hospital, preoperative fasting diminished insulin activity and peripheral glucose uptake; therefore, in the FAST group, preoperative hyperglycaemia occurred and was maintained after surgery during the study period. This study confirmed the results of Sio et al. that preoperative CHO loading provided lower glycaemia and insulinaemia ranges after colectomy [15]. Maintaining postoperative euglycaemia reduces the infection rate and multiple organ failure, while glycaemia $>7 \mathrm{mmol} / \mathrm{L}$ increases mortality 18 -fold [16].

Open colorectal surgery affects the homeostatic balance via extensive surgical stress. Preoperative CHO drink loading is a part of the enhanced recovery after surgery (ERAS) programme, which is applied in colorectal surgery to reduce stress response, PIR and hospital stay [17]. Applying new protocols is not always a simple process. The role of a preoperative $\mathrm{CHO}$ drink has remained controversial. A systematic review of 18 randomised clinical trials established a beneficial effect of preoperative $\mathrm{CHO}$ fluids on PIR in oncologic surgery [18], although Pexe-Machado et al. did not find such an influence in gastrointestinal oncologic surgery [19]. Inconsistencies were due to heterogeneity of the samples, surgical procedures, anaesthetic protocols, evaluated variables and measurement methods. The presented study controlled many of the PIR risk factors via the inclusion and exclusion criteria to minimise the bias. Each patient underwent a preoperative nutritional status assessment using the NRS-2002 score. A score $\geq 3$ identified patients at nutritional risk and those with a metabolic stress response induced by malignant disease, and these patients were excluded from the study to avoid the influence of malnutrition and disease severity on the research results. In our study, preoperative fasting maintained PIR through the observed postoperative period, and the most prominent was on postoperative day 1 . In the $\mathrm{CHO}$ group, PIR 
Table 4 Comparison of perioperative well-being parameters according to the groups and study time points

\begin{tabular}{|c|c|c|c|c|c|c|}
\hline \multirow[t]{2}{*}{ Parameter } & \multirow[t]{2}{*}{ Time } & \multicolumn{2}{|c|}{ FAST group $(n=25)$} & \multicolumn{2}{|c|}{ CHO group $(n=25)$} & \multirow[t]{2}{*}{$p$} \\
\hline & & Mean \pm SD & $95 \% \mathrm{CI}$ & Mean \pm SD & $95 \% \mathrm{CI}$ & \\
\hline \multirow[t]{5}{*}{ Thirst } & $\mathrm{T}_{1}$ & $20.8 \pm 2.2$ & $14.8-18.2$ & $4.2 \pm 3.6$ & $4.8-18.2$ & 0.001 \\
\hline & $\mathrm{T}_{2}$ & $33.6 \pm 4.6$ & $24.2-28.7$ & $7.1 \pm 3.1$ & $24.2-28.8$ & 0.001 \\
\hline & $\mathrm{T}_{3}$ & $41.1 \pm 4.5$ & $18.8-23.6$ & $19.8 \pm 3.9$ & $18.8-23.6$ & 0.001 \\
\hline & $\mathrm{T}_{4}$ & $49.1 \pm 4.7$ & $23.6-28.2$ & $23.1 \pm 3.2$ & $23.6-28.3$ & 0.001 \\
\hline & $\mathrm{T}_{5}$ & $58.4 \pm 3.6$ & $28.3-32.8$ & $27.8 \pm 4.2$ & $28.3-2.8$ & 0.001 \\
\hline \multirow[t]{5}{*}{ Hunger } & $\mathrm{T}_{1}$ & $23.8 \pm 3.0$ & $20.5-23.8$ & $1.6 \pm 2.7$ & $20.5-23.8$ & 0.001 \\
\hline & $\mathrm{T}_{2}$ & $30.5 \pm 3.3$ & $23.7-26.7$ & $5.2 \pm 1.7$ & $23.7-26.8$ & 0.001 \\
\hline & $\mathrm{T}_{3}$ & $45.1 \pm 4.3$ & $27.9-32.3$ & $14.9 \pm 3.3$ & $27.9-32.3$ & 0.001 \\
\hline & $\mathrm{T}_{4}$ & $51.1 \pm 3.5$ & $29.4-33.3$ & $19.6 \pm 3.3$ & $29.4-33.3$ & 0.001 \\
\hline & $\mathrm{T}_{5}$ & $56.8 \pm 5.4$ & $30.3-35.9$ & $23.6 \pm 4.3$ & $30.3-35.9$ & 0.001 \\
\hline \multirow[t]{5}{*}{ Dry mouth } & $\mathrm{T}_{1}$ & $18.0 \pm 1.6$ & $14.5-16.7$ & $2.3 \pm 2.1$ & $14.5-16.7$ & 0.001 \\
\hline & $\mathrm{T}_{2}$ & $29.3 \pm 4.1$ & $22.6-26.2$ & $4.8 \pm 1.9$ & $22.5-26.2$ & 0.001 \\
\hline & $\mathrm{T}_{3}$ & $37.7 \pm 2.8$ & $28.6-31.3$ & $7.7 \pm 2.0$ & $28.5-31.4$ & 0.001 \\
\hline & $\mathrm{T}_{4}$ & $39.7 \pm 4.1$ & $25.6-29.3$ & $12.2 \pm 2.0$ & $25.5-29.3$ & 0.001 \\
\hline & $\mathrm{T}_{5}$ & $46.5 \pm 5.9$ & $24.6-29.6$ & $19.4 \pm 2.1$ & $24.5-29.7$ & 0.001 \\
\hline \multirow[t]{5}{*}{ Weakness } & $\mathrm{T}_{1}$ & $9.8 \pm 3.0$ & $8.6-11.0$ & $0.0 \pm 0.0$ & $8.5-11.0$ & 0.001 \\
\hline & $\mathrm{T}_{2}$ & $25.7 \pm 3.3$ & $12.5-16.5$ & $11.2 \pm 3.6$ & $12.5-16.5$ & 0.001 \\
\hline & $\mathrm{T}_{3}$ & $31.8 \pm 3.0$ & $10.2-13.8$ & $19.8 \pm 3.1$ & $10.2-13.8$ & 0.001 \\
\hline & $\mathrm{T}_{4}$ & $36.7 \pm 3.7$ & $19.3-23.2$ & $15.4 \pm 3.1$ & $19.3-23.2$ & 0.001 \\
\hline & $\mathrm{T}_{5}$ & $42.9 \pm 4.5$ & $27.4-31.7$ & $13.3 \pm 2.7$ & $27.4-31.7$ & 0.001 \\
\hline \multirow[t]{5}{*}{ Anxiety } & $\mathrm{T}_{1}$ & $11.6 \pm 2.9$ & $9.3-12.1$ & $0.9 \pm 1.9$ & $9.3-12.1$ & 0.001 \\
\hline & $\mathrm{T}_{2}$ & $27.6 \pm 4.0$ & $16.2-20.5$ & $9.2 \pm 3.4$ & $16.2-20.5$ & 0.001 \\
\hline & $\mathrm{T}_{3}$ & $32.3 \pm 3.5$ & $19.0-23.6$ & $10.9 \pm 4.3$ & $19.0-23.6$ & 0.001 \\
\hline & $\mathrm{T}_{4}$ & $24.8 \pm 3.4$ & $18.5-21.9$ & $4.6 \pm 2.3$ & $18.5-21.9$ & 0.001 \\
\hline & $\mathrm{T}_{5}$ & $21.6 \pm 3.0$ & $20.4-22.8$ & $0.0 \pm 0.0$ & $20.3-22.9$ & 0.001 \\
\hline \multirow[t]{5}{*}{ Nausea, $n(\%)$} & $\mathrm{T}_{1}$ & $0(0)$ & & $0(0)$ & & 1 \\
\hline & $\mathrm{T}_{2}$ & $7(28)$ & & $1(4)$ & & 0.02 \\
\hline & $\mathrm{T}_{3}$ & $6(24)$ & & $1(4)$ & & 0.04 \\
\hline & $\mathrm{T}_{4}$ & $3(12)$ & & $1(4)$ & & 0.29 \\
\hline & $\mathrm{T}_{5}$ & $0(0)$ & & $0(0)$ & & l \\
\hline \multirow[t]{5}{*}{ Vomiting, $n(\%)$} & $\mathrm{T}_{1}$ & $0(0)$ & & $0(0)$ & & l \\
\hline & $\mathrm{T}_{2}$ & $3(12)$ & & $1(4)$ & & 0.29 \\
\hline & $\mathrm{T}_{3}$ & $0(0)$ & & $0(0)$ & & I \\
\hline & $\mathrm{T}_{4}$ & $1(4)$ & & $1(4)$ & & 1.00 \\
\hline & $\mathrm{T}_{5}$ & $0(0)$ & & $0(0)$ & & l \\
\hline Antiemetic drug dose, $n(\%)$ & & $6(24)$ & & $1(4)$ & & 0.04 \\
\hline
\end{tabular}

Student's $t$ test and $x^{2}$ test were used for the analysis, and $p<0.05$ was considered statistically significant. $S D$, standard deviation; $C I$, confidence interval; FAST group, preoperative fasting group; $C H O$ group, preoperative carbohydrate loading group; $T_{1}$, prior anaesthesia induction; $T_{2}, 0-4 \mathrm{~h}$ after surgery; $T_{3}, 4-8 \mathrm{~h}$ after surgery; $T_{4}, 8-12 \mathrm{~h}$ after surgery; $T_{5}, 12-24 \mathrm{~h}$ after surgery

appeared only on postoperative day 1 . Amer et al. confirmed that CHO loading reduced PIR in elective surgery [20]. A lower HOMA-IR index was reported by Vigano et al. in major abdominal surgery with preoperative $\mathrm{CHO}$ treatment. Vigano's study recorded higher PIR levels compared with our results because various types of abdominal surgery in that study induced different intensities of surgical stress [21].
Possible mechanisms to reduce PIR via a $\mathrm{CHO}$ drink are the activation of glucose transporter 4 on the plasma membrane, improving glycogen synthase activity and the activation of insulin signalling pathways via protein kinase B [22].

In the state of PIR, insulin non-dependent cells such as immunocytes are overloaded with glucose and produce reactive oxygen species that enhance inflammation. Inflammation, in 
Table 5 Mean values of the VAS pain score according to the groups and study time points

\begin{tabular}{|c|c|c|c|c|c|c|}
\hline \multirow[t]{2}{*}{ Parameters } & \multirow[t]{2}{*}{ Time } & \multicolumn{2}{|c|}{ FAST group $(n=25)$} & \multicolumn{2}{|c|}{ CHO group $(n=25)$} & \multirow[t]{2}{*}{$p$} \\
\hline & & Mean \pm SD & $95 \% \mathrm{CI}$ & Mean \pm SD & $95 \% \mathrm{CI}$ & \\
\hline \multirow[t]{5}{*}{ Pain at rest } & $\mathrm{T}_{1}$ & $0.0 \pm 0.0$ & $0.0-0.0$ & $0.0 \pm 0.0$ & $0.0-0.0$ & - \\
\hline & $\mathrm{T}_{2}$ & $3.1 \pm 7.9$ & $-1.8-8.8$ & $32.6 \pm 10.6$ & $-1.8-8.8$ & 0.19 \\
\hline & $\mathrm{T}_{3}$ & $46.2 \pm 9.5$ & $-2.1-8.7$ & $42.9 \pm 9.4$ & $-2.1-8.7$ & 0.22 \\
\hline & $\mathrm{T}_{4}$ & $25.4 \pm 5.1$ & $-2.0-3.7$ & $24.5 \pm 4.9$ & $-2.0-3.7$ & 0.56 \\
\hline & $\mathrm{T}_{5}$ & $6.1 \pm 6.3$ & $-3.0-3.9$ & $5.6 \pm 6.0$ & $-3.0-3.9$ & 0.80 \\
\hline \multirow[t]{5}{*}{ Pain with mobilisation } & $\mathrm{T}_{1}$ & $0.0 \pm 0.0$ & $0.0-0.0$ & $0.0 \pm 0.0$ & $0.0-0.0$ & - \\
\hline & $\mathrm{T}_{2}$ & $40.4 \pm 8.86$ & $-4.0-6.6$ & $39.1 \pm 9.7$ & $-4.0-6.6$ & 0.62 \\
\hline & $\mathrm{T}_{3}$ & $50.5 \pm 10.5$ & $-3.2-8.1$ & $48.0 \pm 9.1$ & $-3.1-8.1$ & 0.38 \\
\hline & $\mathrm{T}_{4}$ & $30.4 \pm 5.1$ & $-2.3-3.9$ & $29.6 \pm 5.7$ & $-2.3-3.9$ & 0.60 \\
\hline & $\mathrm{T}_{5}$ & $10.0 \pm 79$ & $-3.0-5.5$ & $8.7 \pm 6.7$ & $-3.0-5.5$ & 0.55 \\
\hline \multicolumn{2}{|c|}{ Time to first analgesic dose (h) } & $1.9 \pm 1.0$ & $-2.0-0.3$ & $3.1 \pm 1.8$ & $-2.0-0.3$ & 0.006 \\
\hline \multicolumn{2}{|c|}{ Additional analgesic dose, $n(\%)$} & $9(36)$ & & $6(24)$ & & 0.35 \\
\hline
\end{tabular}

Student's $t$ test and $x^{2}$ test were used for the analysis, and $p<0.05$ was considered statistically significant

$S D$, standard deviation; $C I$, confidence interval; FAST group, preoperative fasting group; $C H O$ group, preoperative carbohydrate loading group; $T_{1}$, prior anaesthesia induction; $T_{2}, 0-4 \mathrm{~h}$ after surgery; $T_{3}, 4-8 \mathrm{~h}$ after surgery; $T_{4}, 8-12 \mathrm{~h}$ after surgery; $T_{5}, 12-24 \mathrm{~h}$ after surgery

turn, amplifies PIR in a vicious cycle [23]. In the present study, preoperative fasting was correlated with greater acute-phase protein disturbance, a higher GPS and higher IL-6 levels. A preoperative $\mathrm{CHO}$ drink significantly attenuated the immune reaction but did not have a strong enough effect to stop it. Researchers have found a lower acute phase response after cholecystectomy [24] and lower IL-6 levels after colorectal resection due to a preoperative $\mathrm{CHO}$ drink [25]. A higher GPS score after colorectal surgery predicts cachexia and a poorer survival rate [26]. Increased IL-6 and CRP levels for more than three postoperative days indicate the development of SIRS [27]. By reducing these biomarkers, a preoperative $\mathrm{CHO}$ drink could be effective in the preservation of postoperative immunological homeostasis.

The fasting period before surgery alerts patients' mental and physical conditions. Patients become dehydrated, unable to concentrate and generally unfit. A preoperative $\mathrm{CHO}$ drink is recommended to achieve preoperative euvolemia and caloric intake [28]. In this study, a $\mathrm{CHO}$ drink strengthened patients' general well-being compared with the FAST group. Lower feelings of thirst, hunger and dry mouth were probably primary effects of the $\mathrm{CHO}$ drink related to energy supply and hydration. Reductions in the VAS anxiety and weakness scores were secondary effects. A significant decline from the basal values of the VAS anxiety and hunger scores has been detected after $\mathrm{CHO}$ administration in elective surgery [29]. In our study, the VAS anxiety score declined at 8-12 and 12-24 h after surgery, while the weakness score declined at 12-24 h after surgery. Henrixen et al. found no influence on the VAS well-being score after $\mathrm{CHO}$ administration in colorectal surgery. The anaesthesia protocol in this study included

Table 6 Results of the of surgical clinical outcomes according to the groups

\begin{tabular}{|c|c|c|c|c|c|}
\hline \multirow[t]{2}{*}{ Outcomes } & \multicolumn{2}{|c|}{ FAST group $(n=25)$} & \multicolumn{2}{|c|}{ CHO group $(n=25)$} & \multirow[t]{2}{*}{$p$} \\
\hline & Mean $\pm \mathrm{SD}$ & $95 \% \mathrm{CI}$ & Mean \pm SD & $95 \% \mathrm{CI}$ & \\
\hline Intestinal sounds heard (h) & $56.8 \pm 11.4$ & $3.6-14.9$ & $47.5 \pm 8.1$ & $3.6-14.9$ & 0.002 \\
\hline Time to first flatus (days) & $3.1 \pm 0.5$ & $0.3-0.8$ & $2.5 \pm 0.5$ & $0.3-0.8$ & 0.001 \\
\hline Time to first defecation (days) & $4.0 \pm 0.9$ & $0.4-1.2$ & $3.2 \pm 0.4$ & $0.4-1.2$ & 0.000 \\
\hline Time to oral intake (days) & $4.1 \pm 0.5$ & $0.2-0.8$ & $3.6 \pm 0.5$ & $0.2-0.8$ & 0.001 \\
\hline Time to independent ambulation (days) & $4.2 \pm 0.5$ & $0.3-0.8$ & $3.6 \pm 0.4$ & $0.3-0.8$ & 0.000 \\
\hline Postoperative discharge day & $8.8 \pm 1.1$ & $0.5-1.5$ & $7.7 \pm 0.4$ & $0.5-1.5$ & 0.000 \\
\hline
\end{tabular}

Student's $t$ test was used for the analysis, and $p<0.05$ was considered statistically significant

$S D$, standard deviation; FAST group, preoperative fasting group; $C H O$ group, preoperative carbohydrate loading group 
epidural anaesthesia, which possibly modulated the magnitude of surgical stress and could influence the intervention [30].

In our study, the $\mathrm{CHO}$ drink did not significantly improve the VAS pain score. A prolonged time to the first analgesic dose in the CHO group might have been caused by the improvement in general well-being.

In the present study, the $\mathrm{CHO}$ drink reinforced the surgical outcomes. The postoperative return of gastrointestinal function was faster, and independent ambulation and the postoperative discharge day occurred one day earlier than in the FAST group. CHO treatment reduces protein loss, improves muscle function and promotes an anabolic state that may help in recovery after surgery [31]. A CHO drink helps avoid perioperative hyperglycaemia and alleviates PIR, which are two independent factors of the length of hospital stay [32]. Additionally, reduced anxiety and weakness scores and an earlier oral intake in the $\mathrm{CHO}$ group might be reasons for the earlier independent ambulation and discharge day. A meta-analysis of 21 clinical trials revealed a reduction in the length of hospital stay and PIR with preoperative $\mathrm{CHO}$ treatment in major abdominal surgery [33].

A preoperative $\mathrm{CHO}$ drink has a gastric passage time of less than $2 \mathrm{~h}$ and does not prolong the gastric emptying time [34]. In this study, there were no cases of taste intolerance, aspiration of gastric contents or adverse events connected with the oral fluid intake.

This study has some limitations. The evaluated parameters were monitored up to the second postoperative day. A longer follow-up would determine how long it takes to restore the metabolic and inflammatory parameters to basal values and whether the CHO drink accelerates this return. The obtained results refer only to participants with ASA physical status grades I and II. The inclusion of participants with ASA grade III or IV might be required to optimise the perioperative care and anaesthesia technique. Further research studies are needed to clarify some unresolved issues, e.g., the use of a $\mathrm{CHO}$ drink in patients with a higher ASA grade, diabetes mellitus or obesity.

In conclusion, a CHO supplement is a safe and effective practise in shortening preoperative fasting in open colorectal surgery. A CHO solution used the evening before surgery and $2 \mathrm{~h}$ before the induction of anaesthesia reduces PIR, attenuates the inflammatory response and improves subjective patient well-being. Additionally, a CHO drink allows for the faster return of gastrointestinal function, earlier independent ambulation and earlier postoperative discharge day. $\mathrm{CHO}$ loading did not significantly diminish postoperative pain. The use of preoperative $\mathrm{CHO}$ drinks should be a standard and widespread preoperative care practise, included in institutional protocols and accepted by surgical, anaesthesiologic and nursing teams in elective colorectal surgery.
Author contributions Rizvanović Nermina contributed to the conception and design of the study, the acquisition, analysis and interpretation of the data, and writing the original draft of the manuscript.

Nesek Adam Višnja contributed to the conception and design of the study, interpretation of the data, and review and editing of the manuscript.

Čaušević Senada contributed to conducting research and acquisition of the data.

Dervišević Senad contributed to conducting research and acquisition of the data.

Delibegovic Samir contributed to the critical revision of the manuscript.

All authors read and approved the final manuscript. This manuscript is not being considered by any other journal.

\section{Compliance with ethical standards}

Conflict of interest The authors declare that they have no competing interests.

Statement of human rights All procedures performed in this prospective randomised clinical trial (ClinicalTrials.gov registration ID: NCT03793036) involving human participants were conducted in accordance with the Declaration of Helsinki and its later amendments or comparable ethical standards. Ethical approval was obtained from the institutional ethical committee of Cantonal Hospital Zenica, Faculty of Medicine, University of Zenica (No. 20/1-2-4625/1).

Informed consent Written informed consent was obtained from each participant.

Statement on the welfare of animals This article does not contain any studies with animals performed by any of the authors.

Open Access This article is distributed under the terms of the Creative Commons Attribution 4.0 International License (http:// creativecommons.org/licenses/by/4.0/), which permits unrestricted use, distribution, and reproduction in any medium, provided you give appropriate credit to the original author(s) and the source, provide a link to the Creative Commons license, and indicate if changes were made.

\section{References}

1. Scott MJ, Baldini G, Fearon KC, Feldheiser A, Feldman LS, Gan TJ, Ljungqvist O, Lobo DN, Rockall TA, Schricker T, Carli F (2015) Enhanced recovery after surgery (ERAS) for gastrointestinal surgery, part 1: pathophysiological considerations. Acta Anaesthesiol Scand 59:1212-1231. https://doi.org/10.1111/aas. 12601

2. Ljungqvist O, Jonathan E (2012) Rhoads lecture 2011: insulin resistance and enhanced recovery after surgery. JPEN J Parenter Enteral Nutr 36:389-398. https://doi.org/10.1177/ 0148607112445580

3. Akbarzadeh M, Eftekhari MH, Shafa M, Alipour S, Hassanzadeh J (2016) Effects of a new metabolic conditioning supplement on perioperative metabolic stress and clinical outcomes: a randomized, placebo-controlled trial. Iran Red Crescent Med J 18:e26207. https://doi.org/10.5812/ircmj.26207

4. Jodlowski T, Dobosz M (2014) Preoperative fasting - is it really necessary? Pol Przegl Chir 86:100-105. https://doi.org/10.2478/ pjs-2014-0019 
5. Nygren J (2006) The metabolic effects of fasting and surgery. Best Pract Res Clin Anaesthesiol 20:429-438. https://doi.org/10.1016/j. bpa.2006.02.004

6. Kratzing C (2011) Pre-operative nutrition and carbohydrate loading. Proc Nutr Soc 70:311-315. https://doi.org/10.1017/ S0029665111000450

7. Sada F, Krasniqi A, Hamza A, Gecaj-Gashi A, Bicaj B, Kavaja F (2014) A randomized trial of preoperative oral carbohydrates in abdominal surgery. BMC Anesthesiol 14:93. https://doi.org/10. 1186/1471-2253-14-93

8. Gianotti L, Biffi R, Sandini M, Marrelli D, Vignali A, Caccialanza R, Viganò J, Sabbatini A, Di Mare G, Alessiani M, Antomarchi F, Valsecchi MG, Bernasconi DP (2018) Preoperative oral carbohydrate load versus placebo in major elective abdominal surgery (PROCY): a randomized, placebo-controlled, multicenter, phase III trial. Ann Surg 267:623-630. https://doi.org/10.1097/SLA. 0000000000002325

9. Witasp A, Nordfors L, Schalling M, Nygren J, Ljungqvist O, Thorell A (2010) Expression of inflammatory and insulin signaling genes in adipose tissue in response to elective surgery. J Clin Endocrinol Metab 95:3460-3469. https://doi.org/10.1210/jc.20092588

10. Perrone F, da-Silva-Filho AC, Adorno IF, Anabuki NT, Leal FS, Colombo T, da Silva BD, Dock-Nascimento DB, Damiao A, de Aguilar-Nascimento JE (2011) Effects of preoperative feeding with a whey protein plus carbohydrate drink on the acute phase response and insulin resistance: a randomized trial. Nutr J 10:66-72. https:// doi.org/10.1186/1475/-2891-10-66

11. Costa MD, Vieira de Melo CY, Amorim AC, Cipriano Torres Dde O, Dos Santos AC (2016) Association between nutritional status, inflammatory condition, and prognostic indexes with postoperative complications and clinical outcome of patients with gastrointestinal neoplasia. Nutr Cancer 68:1108-1114. https://doi.org/10.1080/ 01635581.2016 .1206578

12. Gomez de Lima KV, Maio R (2012) Nutritional status, systemic inflammation and prognosis of patients with gastrointestinal cancer. Nutr Hosp 27:707-714. https://doi.org/10.3305/nh/2012.27.3.5567

13. Ishizuka M, Nagata $H$, Takagi K, Iwasaki $Y$, Shibuya N, Kubota K (2016) Clinical significance of the C-reactive protein to albumin ratio for survival after surgery for colorectal Cancer. Ann Surg Oncol 23:900-907. https://doi.org/10. 1245/s10434-015-4948-7

14. Kondrup J, Rasmussen HH, Hamberg O, Stanga Z, Ad Hoc ESPEN Working Group (2003) Nutritional risk screening (NRS 2002): a new method based on an analysis of controlled clinical trials. Clin Nutr 22:231-236. https://doi.org/ 10.1016/S0261-5614(02)00214-5

15. Sio CA, Jung K, Kang SB, Kim DW, Oh HK, Yoon M (2015) The evaluation of preoperative oral carbohydrate-rich solution effects on insulin resistance in patients undergoing colectomy. J Clin Nutr 7: 62-67. https://doi.org/10.15747/jen.2015.7.2.62

16. Kang ZQ, Huo JL, Zhai XJ (2018) Effects of perioperative tight glycemic control on postoperative outcomes: a meta-analysis. Endocr Connect 7:316-327. https://doi.org/10.1530/EC-18-0231

17. Gustafsson UO, Scott MJ, Schwenk W, Demartines N, Roulin D, Francis N, McNaught CE, Macfie J, Liberman AS, Soop M, Hill A, Kennedy RH, Lobo DN, Fearon K, Ljungqvist O, Enchanced Recovery After Surgery (ERAS) Society for Perioperative Care; European Society for Clinical Nutrition and Metabolism (ESPEN); International Association for Surgical Metabolism and Nutrition (IASMEN) (2013) Guidelines for perioperative care in elective colonic surgery: Enhanced Recovery After Surgery (ERAS) Society recommendations. World J Surg 37:259284. https://doi.org/10.1007/s00286-018-4844-y
18. Pinto AS, Grigoletti SS, Marcadenti A (2015) Fasting abbreviation among patients submitted to oncologic surgery: systematic review. Arq Bras Cir Dig 28:70-73. https://doi.org/10.1590/S010267202015000100018

19. Pexe-Machado PA, de Oliveira BD, Dock-Nascimento DB, de Aguilar-Nascimento JE (2013) Shrinking preoperative fast time with maltodextrin and protein hydrolysate in gastrointestinal resections due to cancer. Nutrition 29:1054-1059. https://doi.org/10. 1016/j.nut.2013.02.003

20. Amer MA, Smith MD, Herbison GP, Plank LD, McCall JL (2017) Network meta-analysis of the effect of preoperative carbohydrate loading on recovery after elective surgery. Br J Surg 104:187-197. https://doi.org/10.1002/bjs.10408

21. Vigano J, Cereda E, Caccialanza R, Carini R, Cameletti B, Spampinato M, Dionigi P (2012) Effects of preoperative oral carbohydrate supplementation on postoperative metabolic stress response of patients undergoing elective abdominal surgery. World J Surg 36:1738-1743. https://doi.org/10.1007/s00268-012-1590-4

22. Tamura T, Yatabe T, Kitagawa H, Yamashita K, Hanazaki K, Yokoyama M (2013) Oral carbohydrate loading with 18\% carbohydrate beverage alleviates insulin resistance. Asia Pac J Clin Nutr 22:48-53. https://doi.org/10.6133/apjen. 2013.22.1.20

23. Duggan EW, Carlson K, Umpierrez GE (2017) Perioperative hyperglycemia management: an update. Anesthesiology 126:547560. https://doi.org/10.1097/ALN.0000000000001515

24. Dock-Nascimento DB, de Aguilar-Nascimento JE, Magalhaes Faria MS, Caporossi C, Slhessarenko N, Waitzberg DL (2012) Evaluation of the effects of a preoperative 2-hour fast with maltodextrine and glutamine on insulin resistance, acute phase response, nitrogen balance, and serum glutatione after laparoscopic cholecystectomy: a controlled randomized trial. JPEN J Parenter Enteral Nutr 36:43-52. https://doi.org/10. $1177 / 0148607111422719$

25. Zelic M, Stimac D, Mendrila D, Tokmadzic VS, Fisic E, Uravic M, Sustic A (2012) Influence of preoperative oral feeding on stres response after resection for colon cancer. Hepatogastroenterology 59:1385-1389. https://doi.org/10.5754/hge10556

26. Gomez de Lima KV, Maio R (2012) Nutritional status, systemic inflammation and prognosis of patients with gastrointestinal cancer. Nutr Hosp 27:707-714. https://doi.org/10.3305/nh/2012.27.3.5567

27. Sartelli M, Catena F, Abu-Zidan FM, Ansaloni L, Biffl WL, Boermeester MA, Ceresoli M, Chiara O, Coccolini F, de Waele JJ, di Saverio S, Eckmann C, Fraga GP, Giannella M, Girardis M, Griffiths EA, Kashuk J, Kirkpatrick AW, Khokha V, Kluger Y, Labricciosa FM, Leppaniemi A, Maier RV, May AK, Malangoni M, Martin-Loeches I, Mazuski J, Montravers P, Peitzman A, Pereira BM, Reis T, Sakakushev B, Sganga G, Soreide K, Sugrue M, Ulrych J, Vincent JL, Viale P, Moore EE (2017) Management of intraabdominal infections: recommendations by the WSES 2016 consensus conference. World J Emerg Surg 12:22. https:// doi.org/10.1186/s13017-017-0132-7

28. Weimann A, Braga M, Carli F, Higashiguchi T, Hübner M, Klek S, Laviano A, Ljungqvist O, Lobo DN, Martindale R, Waitzberg DL, Bishoff SC, Singer P (2017) ESPEN guideline. Clin Nutr 36:623650. https://doi.org/10.1016/j.clnu.2017.02.013

29. Hausel J, Nyrgen J, Lagerkranser M, Hellstrom PM, Hammarqvist F, Almstrom C, Lindh A, Thorell A, Ljungqvist O (2001) A carbohydrate-rich drink reduces preoperative discomfort in elective surgery patients. Anesth Analg 93:1344-1350. https://doi.org/10. 1097/00000539-200111000-00063

30. Henriksen MG, Hessov I, Dela F, Vind Hansen H, Haraldsted V, Rodt SA (2003) Effects of preoperative oral carbohydrates and peptides on postoperative endocrine response, mobilization, nutrition and muscle function in abdominal surgery. Acta Anaesthesiol 
Scand 47:191-199. https://doi.org/10.1034/j.1399-6576.2003. 00047.x

31. Burgess LC, Phillips SM, Wainwright TW (2018) What is the role of nutritional supplements in support of total hip replacement and total knee replacement surger a systematic review. Nutrients 10: 820. https://doi.org/10.3390/nu10070820

32. Fawcett WJ, Ljungqvist O (2017) Starvation, carbohydrate loading, and outcome after major surgery. BJA Educ 17:312-316. https://doi.org/10.1093/bjaed/mkx015

33. Awad S, Varadhan KK, Ljungqvist O, Lobo DN (2013) A metaanalysis of randomised controlled trials on preopoerative oral carbohydrate treatment in elective surgery. Clin Nutr 32:34-44. https://doi.org/10.1016/j.clnu.2012.10.011

34. Sarin A, Chen L, Wick EC (2017) Enhanced recovery after surgery - preoperative fasting and glucose loading - a review. J Surg Oncol 116:578-582. https://doi.org/10.1002/jso.24810

Publisher's note Springer Nature remains neutral with regard to jurisdictional claims in published maps and institutional affiliations. 